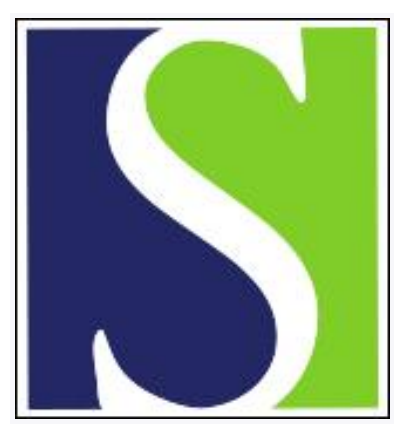

Scand J Work Environ Health 2009;35(6):421-428

https://doi.org/10.5271/sjweh.1356

Published online: 01 Oct 2009, Issue date: 00 Dec 2009

Quality of working life and organizational performance - two sides of the same coin?

by Pot FD, Koningsveld EAP

Affiliation: Department of Business Administration, Radboud University Nijmegen, Nijmegen, the Netherlands. f.pot@fm.ru.nl

The following articles refer to this text: 2009;35(6):401-402;

2010;36(4):269-271

Key terms: discussion paper; organizational performance; quality; social innovation; working life; worklife; workplace development

This article in PubMed: www.ncbi.nlm.nih.gov/pubmed/19806274 


\section{Quality of working life and organizational performance - two sides of the same coin?}

by Frank D Pot, PhD ${ }^{1}$ Ernst AP Koningsveld, MSc, Eur Erg ${ }^{2}$

Pot FD, Koningsveld EAP. Quality of working life and organizational performance - two sides of the same coin? Scand J Work Environ Health. 2009;35(6):421-428.

Objective This discussion paper presents the debate on the theoretical and practical claim that a simultaneous improvement in the quality of working life and organizational performance can be achieved by workplace development.

Methods We discuss theories that support this claim or could provide additional support, and mention six "programs" on workplace development or social innovation in European countries. We present the results of evaluation studies in Finland, Germany, Ireland, and the Netherlands.

Results A correlation of 0.50 was found between the quality of working life and organizational performance. All evaluations showed that the simultaneous improvement in the quality of working life and performance was achieved in a number of, but not all, projects. The percentage of successful projects is not always clear and depends on which aspects of quality of working life and performance were taken into account. Our estimation would be $25-50 \%$. Which factors are important for success? With the exception of the commitment of top management and employee participation, other determinants were difficult to distinguish due to differences in research designs and programs.

Conclusions Important issues for discussion remain with respect to theory, research and practical approaches. Research should be more concerned with patterns of independent variables and how organizations deal with dilemmas. The most important pitfall of workplace development appears to be taking a top-down as opposed to a participatory approach involving employees and their supervisors in projects. National programs seem to be more effective than the initiatives of separate stakeholders groups.

Key terms discussion paper; social innovation; worklife; workplace development.

Recent initiatives, including national programs, on "workplace innovation and development" in a number of European countries (eg, Finland, Germany, Ireland, UK, Belgium, the Netherlands) claim improvement in the quality of working life as well as enhanced organizational performance $(1,2)$. But critical assessments of earlier programs, such as "high performance work systems", have shown that the outcomes of such programs are uncertain or even unwarranted (3), and sometimes disappointing for employees and unions (4). Other sources indicate that conclusions cannot be drawn because of the methodological limitations of the research, such as inadequate measurement of interventions, contamination between interventions and performance, and the paucity of longitudinal studies all of which make causal inference dubious (5). Sometimes one aspect of the quality of working life can be positive and another negative. Data from the European Working Conditions Survey (EWCS) 2000-2001 indicate, for instance, that teamwork goes together with a better learning environment (paid training, continuous learning, complex tasks) as opposed to working alone (6). Nevertheless, team workers are not more satisfied with their working conditions. They report more often an increased pace of work and having to work to tight deadlines, and indicate that their health is affected by work. In a German research project on "concepts of innovative workplace policy", these ambivalences of modern teamwork were found as well (7).

1 Institute for Management Research, Centre for Innovation Studies, Radboud University Nijmegen, the Netherlands.

2 TNO Quality of Life / Work and Employment, Hoofddorp, the Netherlands.

Correspondence to: Professor FD Pot, Department of Business Administration, Radboud University Nijmegen, PO Box 9108, NL-6500 HK Nijmegen, the Netherlands. [E-mail: f.pot@fm.ru.nl] 
In this paper, we present mainly recent surveys with opinions of stakeholders concerning interventions and effects, sometimes meant to be a program evaluation (eg, Finland). Search procedures did not produce the relevant references, so we had to rely on our own knowledge of researchers, institutes, and networks. We did not include research that was only directed at the costs of absenteeism (lost working days due to illness) or presenteeism (a decline in productivity at work because of illness). This is covered in two other articles in this volume. Nor did we include the performance effects of working conditions, such as noise, lighting, and indoor air quality, because the programs we discuss were not focused on these topics and we wanted to restrict ourselves.

The experiences in these programs and the debate might indicate that occupational safety and health (OSH) and other professionals could be more successful if they joined forces. This is even more important as the dominant trend in new forms of work organization appears to be "lean production", indicating growing stress risks for employees (8).

In this discussion paper, we explore the actual societal conditions (eg, economic and demographic trends, policies, stakeholders) and theoretical support for the claim that quality of working life and performance are closely linked and also discuss some evaluation studies that have already been executed.

\section{Quality of working life and performance}

Regarding the quality of working life, we look particularly at work organization (in particular job autonomy and teamwork), human resource management (eg, competence development), style of management (eg, participation, trust, control), and workplace ergonomics. These aspects of the quality of working life are psychosocial and physical risk factors for occupational health (eg, stress, wellbeing, musculoskeletal disorders). Performance can be labor productivity per hour, process optimization, product innovation, quality of goods and services, or customer service for example. We do not use strict definitions because we refer to projects and programs that applied slightly different definitions and variables. See the references in the paragraph "Empirical evidence to date".

Focusing on organizational performance does not automatically mean that occupational health is considered less important. First of all, health is a value in itself. That is why prevention of occupational diseases, accidents, and work-related complaints is important and why - generally speaking - the linked costs are justifiable.

A second reason for health protection is to reduce the costs that are caused by poor working conditions, on both corporate and societal levels. A growing number of companies have experienced that investments in prevention pay off $(9,10)$.

Some companies and public organizations have extended their policies to health promotion and vitality of the workforce as part of their corporate social responsibility. We will go one step further and argue that many of the preventive measures also contribute to enhancing performance and innovation if interventions for prevention on the one hand, and redesign for better performance on the other hand, are purposefully combined.

For instance, organizational commitment can be brought about by an organizational design that provides job autonomy, possibilities for consulting others, and learning opportunities. These are exactly the same measures that are recommended to reduce psychological stress risks by implementing "prevention at the source" (11). People do not suffer from severe strain because of problems and disturbances in their work but rather because they are unable to solve them. This is about discrepancies, for example, between: quantitative job demands and available time or staff; qualitative job demands and education or training; problems and disturbances and support from supervisors and colleagues; and complexity of the job and control capacity.

The same holds for ergonomic design of workplaces. This aims not only to prevent musculoskeletal disorders (eg, allowing better postures and movements; reducing lifting) and improve health (physical exercise) but also to enhance productivity (eg, easier and faster handling and processing, better lay-out), in particular if the design and implementation processes are participatory $(10,12)$.

\section{Political urgency}

The possibility of simultaneous improvement in the quality of working life and performance is even more important as productivity and innovation are back on the political agenda of European Union (EU) countries.

A growing number of countries are conducting or developing some kind of program (www.workinnet.org), the focus of which is primarily on labor productivity, development of competences, and the quality of working life. Examples of program titles include: Workplace Development (Finland); Innovative Work Design and Innovation Capacity (Germany); Social Innovation (the Netherlands and Belgium); and Workplace Innovation (Ireland). These organizational- and sectoral-level policies are connected to policies on the national and European level concerning flexicurity (employment, education, and social security) and innovation. Key concepts include "dynamic management" (absorption of external knowledge), "working smarter" and "utilization of skills and competences". 
The ongoing national programs in Europe are different. Some of them are directed by the government, which supplies substantial money to stimulate action and research (eg, Finland, Germany, Ireland). In other countries, the government is neither leading nor financially at the forefront. In these countries (eg, Belgium, the Netherlands, the UK), social partners and companies, supported by consultants and researchers, take the initiative. This latter model could be a risk. Evaluation of action research programs of the 1990s showed that, in the "best practice model" for national workplace development, the strategic justification should primarily arise from macro-level industrial policy issues, rather than industrial relations or the research and development system (13). But it is now 15 years later and, as far as we can see, social partners - at least in the Netherlands - are determined to keep the lead in this process, facilitated to some extent by the Dutch government and the European Social Fund (14).

There are three main reasons for the emerging attention to workplace development that may apply to most European countries. Firstly, there is a need to enhance labor productivity to maintain current welfare and social security levels in the near future with fewer people in the workforce due to an ageing population. Productivity is no longer a taboo subject in collective bargaining; the debate is on finding a balance between "working harder", "working more hours", and "working smarter".

Secondly, there is a need to develop and utilize the skills and competences of the potential workforce to increase the added-value as part of a competitive and knowledge-based economy. The EU draws attention to the need to foster increased skills and "high quality jobs" that are expected to contribute to employee wellbeing, high quality products and services, and enhanced productivity and innovation.

Thirdly, private and public work organizations can only fully benefit from technological innovation if it is embedded in workplace development (eg, making technology work through proper organization, dynamic management, competence development, and commitment and involvement of employees). Technological innovation and research are good in most European countries and sometimes excellent. However, the utilization of new knowledge for the innovation of products, services and processes (or - to put it another way - the absorptive capacity of organizations) is rather weak; this is called the "innovation paradox" or "technology transfer gap". This is supported by research showing that workplace development itself appears to be more important for innovation successes than technological innovation. For example, research from Erasmus University/ Rotterdam School of Management into industrial sectors in the Netherlands showed that technological innovation explained $25 \%$ of success in radical innovation, while workplace development ("sociale innovatie" in Dutch) was responsible for $75 \%$ (15). In the European Manufacturing Survey of 3000 companies, the effects of product, service, technological, and organizational innovation ${ }^{3}$ have been compared. Only organizational innovation has positive effects on all performance indicators (17).

The financial and economic crisis has not changed these three arguments although it has become more difficult to connect short-term solutions (ie, markets and costs) with long-term objectives (ie, innovation and developing competences).

But although there are enough reasons to develop workplaces from the point of view of prevention and performance, it is not an easy job to do. There are a number of dilemmas facing employees and their representatives with respect to their involvement in and commitment to workplace development. These include the long- and short-term effects (eg, employment) and getting more responsibility for, but not more participation in, decision-making.

The employer/management side also faces dilemmas, for example: the benefits of workplace development appear later than the results of short-term budget cuts; bonuses stimulate short-term thinking; social innovation is more complex than technological innovation; and sharing knowledge and power is not easy. The argument of many executives, who claim to be imprisoned by iron economic laws dictating them to match employment practices offered by their lowest-cost competitors, is contradicted by research findings (18).

To cope with these dilemmas, a good starting point in a number of countries (such as Finland, Germany and the Netherlands) is that unions and employers' organizations have a tradition of cooperation and mutual consultation.

\section{Supporting theories}

Of course there is some evidence for the "happy-productive worker hypothesis" that happy workers are assumed to perform better. Judge (19) found a correlation of 0.30 between satisfaction and self-reported productivity in their meta-analysis of 312 studies covering

3 Compared to workplace development, the concept of organizational innovation as it is used here is confined to: teamwork, task integration, decentralization, continuous improvement of processes, and segmentation of production (16). 
54000 workers. But, as Taris (20) argues, this correlation is still weak, and might be explained by other variables, such as work organization, and does not allow for conclusions to be drawn on performance or productivity at a departmental or organizational level.

The job demands-control model argues that - to understand performance - a proper work organization is more important than job satisfaction (21). High job demands and control provide opportunities for learning. On the contrary, high demands and low control is a stress risk that inhibits learning. However, in this theory, control is only measured by job autonomy and skill discretion (ie, freedom of action and the opportunity to use one's capabilities). This could be called "internal control capacity". But discussing work organization and targets is even more important for innovation; it requires control on another level and could be called "external control capacity" (ie, participation in decision-making), as elaborated in modern socio-technology (22), the action regulation theory (23) and theories of the innovative firm (24). In our opinion, external control capacity should be added to monitoring instruments such as the European Working Conditions Survey.

A second criticism of the job demands-control model is that the relationship between learning, on the one hand, and productive and innovative behavior, on the other hand, is not self-evident and poorly developed in existing theories. A lot of work is still to be done here. We can learn from different approaches such as the resource-based view, which assumes that an organization achieves better performance than its direct competitors through the development of specific resources (ie, skills and competences, knowledge, technology, work organization, and culture) $(25,26)$. Also of interest is the social capital theory on how proper interactions and well-functioning networks in organizations affect performance and health positively (27).

\section{Empirical evidence to date}

So far there are only a limited number of scientific studies available (all of them surveys) asking stakeholders their opinion on the effects of interventions.

Some of these did not include quality of working life aspects linked with performance indicators. A survey in Finland among 5270 employees confirmed the expected positive effects of workplace development on quality of working life but did not cover performance outcomes (28). An Irish research project among chief executive officers and human resource managers of 132 companies in manufacturing and services showed higher productivity and more innovation of products and services. However, quality of working life was only measured as a decrease in personnel turnover and was considered by the authors to be an indicator of increased wellbeing (29). Dutch research into 650 small- and medium-sized enterprises indicated that companies with workplace development projects achieve higher productivity and financial results compared to those that do not implement this kind of project. However, the outcomes regarding quality of working life were not measured except for employment, which, in most cases, was extended (30).

Some studies have covered both quality of working life and performance. In the Finnish workplace development program, performance encompassed: (i) productivity, (ii) quality of goods and services, (iii) quality of operations, (iv) flexible customer service, and (v) smooth running of operations. Quality of working life comprised: (i) cooperation between management and staff, (ii) team-like working processes, (iii) social relations in the workplace, (iv) mental wellbeing, and (v) the development of vocational skills. In an evaluation of part of the Finnish program [312 projects (31)], quality of working life and performance appeared to be correlated (Pearson's $r=0.501)$. In another evaluation of 409 projects in the same program and using the same methodology $(32,33), 115$ organizations improved quality of working life as well as performance, while 31 were negative on both factors. The differences between those organizational groups were difficult to explain due to many situational factors with the exception of one process indicator, namely staff participation. Personnel in the "weaker" group (ie, negative on both factors) was never the initiator and participated poorly in the development process.

A different approach is the Finnish High-Involvement Innovation Practice Survey. One evaluation looked at a selected group of 71 projects in the private and the public sector, for which measurements before ("entry") and after ("exit") the project were available (34). In workplaces where teams existed, employees reported improvements in (i) being directly responsible for the quality of their work, (ii) performing several tasks, (iii) having direct connections with other teams in the organization and parties outside the workplace, (v) the continuous development of operations, (vi) product/service development, and (vii) the ability to choose their own leaders. Employees did not report any improvement in either their ability to decide their day-to-day tasks or select their team members. A more recent evaluation using the same methodology (107 projects until 2008) showed a clear improvement in the use of information sharing and personnel competence practices. Still no significant change in employees' ability to decide their day-to-day and weekly tasks was found (35). From our theoretical point of view concerning the balance between job demands and control capacity, it seems that responsibility increases as a result 
of workplace development, but that control capacity does not. This could be a risk for psychological stress, which would be inconsistent with the hypothesis of the simultaneous improvement of performance and quality of working life.

In Germany, insurance firm AOK's management survey of 212 partner companies has provided interesting findings (9). In those companies (covering production sectors as well as trade and services), a wide variety of issues were examined, concerning - among others - physical workload, sickness absenteeism, ergonomics, work organization, safety, style of leadership, and stress. Health protection was optimized (in $60 \%$ of the companies) and absenteeism had dropped. Assessed by management, performance results were substantial. For example, payment to sick people dropped; productivity increased (in about $50 \%$ of cases); processes were optimized; customer satisfaction increased; failure rates were lower; quality and innovation improved (in about $30 \%$ of cases), and the employability of staff increased (in about $30 \%$ of cases).

In the Netherlands, research organization TNO's Work and Employment department is engaged with a number of projects which aim to improve performance and prevention. Of these, 18 have been evaluated (36). The cases are diverse, covering ergonomically designed hand tools, assembly work, an integrated health program, and job enrichment amongst others. The estimated return on investment was $1-3$ years. In the review, the benefits were split into two categories: (i) traditional OSH gains (eg, injury and accident prevention and reduced absenteeism and disability), versus (ii) "core business values" (eg, productivity, lower direct costs, extra output, lower failure costs, improved quality). Despite the fact that almost all projects started from the OSH perspective, in all but one case, both core business and OSH benefits occurred as a result of the intervention. However, the core business values of 14 of the 18 cases exceeded the OSH benefits; in ten of these, the core business benefits represented more than $90 \%$ of the total benefits. In only two cases, the OSH benefits exceeded the core business benefits.

\section{Discussion}

\section{Success factors and/or dilemmas}

In a growing number of countries and sectors of industry, it is considered a matter of urgency to develop all competences of the potential workforce and increase labor productivity by working smarter. The recent financial and economic crisis has not affected that conviction. In fact, it is an additional reason to invest in the simultaneous improvement in the quality of working life and performance through interventions in the domain of workplace development. However we are also aware of the existing skepticism among people who believe that the impact of technology and markets is far more important for performance, or those who consider the quality of working life as a goal or value separate from performance.

It is difficult to draw general conclusions from the theories and research presented here because concepts, measurements, and research designs differ considerably. Therefore, much of this concluding section consists of issues for further debate or research.

Nevertheless, the results of the studies summarized herewith convince us that improvements in both the quality of working life and organizational performance can go together very well. The percentage of successful projects was not always clear and depended on which aspects of quality of working life and performance were taken into account. Our estimation of a successful outcome would be $25-50 \%$. The best option for projects is a combined focus on quality in working life and performance. But, as the Dutch examples show in particular, there are also performance effects when the project focuses on quality of working life and vice versa. However, the empirical evidence shows that simultaneous improvement in the quality of working life and organizational performance is not achieved in all cases. The outcomes are uncertain. However, it is difficult to identify the determining factors. Conditions for success and failure appear to be complex and partly dependent on local circumstances. The commitment of management combined with the participation of the employees is definitely one important condition for success in both areas. It seems difficult to find a list of success factors or best practices that could be copied. This implies that looking for a list of success factors - the "universalistic perspective" as Delery \& Doty (37) call it - might not be fruitful. It seems that we could explain more if our theories were concerned with "how the pattern of multiple independent variables is related to a dependent variable rather than with how individual independent variables are related to the dependent variable" (37, p804), the so-called "configurational perspective".

Maybe Prud'homme van Reine \& Dankbaar (38) are right when they say that it is not realistic to define a list of success factors in order to develop a recipe for innovative cultures; this might even result in the creation of myths. They argue that organizations have to deal with nine dilemmas: (i) strong identification with own culture versus being sensitive to diversity, (ii) incremental versus radical innovation, (iii) technology push versus market pull, (iv) possibilities available to big companies versus those of small companies, (v) open versus closed innovation, (vi) egalitarian versus hierarchical management style, (vii) process orientation versus room for creativity and entrepreneurship, (viii) individual performance 
versus collaboration in teams, and (ix) taking a shortversus long-term perspective. The ways in which organizations successfully deal with these dilemmas are very different, depending on many contingencies such as products, markets, technology, staff, industrial relations, and legislation. As an example, they refer to an analysis of how Toyota deals with dilemmas and sometimes consciously creates contradictions and paradoxes to move forward. The automotive firm (i) moves slowly, yet takes big leaps; (ii) grows steadily, yet is a paranoid company; (iii) has efficient operations, but uses employees' time in seemingly wasteful ways; (iv) is frugal, but splurges on key areas; (v) insists internal communications be simple, but builds complex social networks; and (vi) has a strict hierarchy, but gives employees freedom to push back (39). This could be an extension of our approach to stakeholder dilemmas as described earlier.

\section{Issues for further debate}

Theory and research. Other important issues for discussion remain. In the next paragraphs, we summarize the highlights. Our arguments can of course be found in the preceding paragraphs.

The relation between job demands-control capacity, on the one hand, and stress risks and learning opportunities, on the other hand, is well documented. Although there is some evidence for the relation between learning and performance, and for the relation between learning and innovation on a personal and organizational level, the theoretical explanations for these relations are rather weak and need elaboration.

Most monitoring instruments covering control capacity include only internal control capacity (job autonomy). However, learning is probably best stimulated by external control capacity (regarding strategic decisions, work organization, and targets). To investigate that relation, apart from job autonomy, we recommend the inclusion of external control capacity in monitoring instruments.

People with active jobs are not expected to have serious work-related problems, at least from a theoretical point of view. However, new work organization (mobile work), the changing work-life balance, and new control mechanisms (employee as entrepreneur) require attention to theoretically unexpected effects such as work-related stress among professionals with highdemand, high-control jobs, part of them referred to as knowledge workers.

It may be interesting to add elements of strategic management theory, such as the resource-based view and modern socio-technology to the job demands-control model. The same holds true for social capital. All these approaches have work organization at the centre of their models.

Many research projects are focused on either quality of working life or performance. As a consequence, there is no opportunity to measure simultaneous effects. Therefore, in evaluation studies, one should look at quality of working life as well as performance indicators.

Moreover, the diversity of concepts and measurements make it difficult to draw general and firm conclusions from research. Harmonizing concepts and measurements in international comparative and multidisciplinary research is thus recommended.

Finally, the acquisition (research institutes) or provision (funding agencies) of funding for longitudinal research is needed to improve causal explanations. Research is necessary to understand which interventions have long lasting effects on both organizational performance and quality of working life.

Interventions. The most interesting lesson gleamed from the studies mentioned in this paper is that management commitment combined with employee participation is the key condition for success in improving quality of working life and performance. An important pitfall appears to be top-down as opposed to participatory projects, involving employees and their supervisors.

Stakeholders in organizations have, to some extent, varying interests and face different dilemmas that may cause conflicts and stagnation in bargaining and implementation processes. To deal with these, creating a common vision on a higher, more abstract level and implementing trust and reciprocal risk management can help. It will take time to establish these conditions.

Moreover, each group of professionals has its own focus, interventions, research methodology, and journals. Often, the results of their efforts are suboptimal because they do not take related issues sufficiently into account. Better outcomes can be achieved if management, OSH professionals and organizational experts join forces.

(Inter)national policies. Workplace innovation and development projects should be embedded in macro-level policies (education, labor market, social security, and innovation). ${ }^{4}$ For example, talent development allows for a more flexible organization and contributes to a more flexible labor market. Job flexibility must be supported by the social security system and collective agreements. In addition, a high-quality education system is needed to ensure high-quality jobs while national innovation strate-

4 From an analytical point of view, the concept of "flexicurity" on the European and national level can be related to the concept of "workplace development" on an organizational level. 
gies should focus not only on technological innovation but also workplace development.

National programs (collaboration of government, social partners, consultants, and research institutes) seem to generate more projects than activities of separate stakeholders. Although organizations are responsible for their own future, some public funding appears to be very effective in stimulating action, research, and dissemination.

\section{Acknowledgements}

The research leading to these results has received funding from the European Community's Seventh Framework Programme (FP7/2007-2013) under grant agreement number $200549 \mathrm{EcOSH}$.

\section{References}

1. Alasoini T, Ramstad E, Hanhike T, Lahtonen M. European programmes on work and labour innovation - a benchmarking approach. Helsinki/Bonn: WORK-IN-NET; 2005.

2. Hakansta C, Abrahamson K, editors. Workplaces of the future. Stockholm/Bonn: WORK-IN-NET; 2008.

3. Godard J. A critical assessment of the high-performance paradigm. Br J Ind Rel. 2005;42(2):349-78.

4. Osterman P. Work reorganization in an era of restructuring: trends in diffusion and effects on employee welfare. Ind Labor Relat Rev. 2000;53(2):179-6.

5. Wall TD, Wood SJ. The romance of human resource management and business performance, and the case for big science. Hum Relat. 2005;58(4):429-62.

6. European Foundation for the Improvement of Living and Working Conditions. Teamwork and high performance work organisation. Dublin: European Foundation for the Improvement of Living and Working Conditions; 2007.

7. Balzert S, Kuhlmann M, Sperling HJ. Konzepte innovativer Arbeitspolitik: zusammenfassende Ergebnisse einer Untersuchung [Concepts of innovative workplace policy: summary of the results of a research project]. SOFIMitteilungen. 2003;31:7-31.

8. Oeij P, Dhondt S, Wiezer N. Conditions for low stress-risk jobs: Europe's case. Eur J Soc Q. 2006;6(2):81-108.

9. Bonitz D, Eberle G, Lück P, editors. Wirtschaftlicher Nutzen von betrieblicher Gesundheitsförderung aus der Sicht von Unternehmen [Economic benefits of health promotion from the point of view of the company]. Bonn (Germany): AOKBundesverband; 2007.

10. Vink P, Koningsveld EAP, Molenbroek JF. Positive outcomes of participatory ergonomics in terms of greater comfort and higher productivity. Appl Ergon. 2006;37:537-46.
11. Pot F, Peeters M, Vaas F, Dhondt S. Assessment of stress risks and learning opportunities in the work organisation. Eur Work Organisat Psychologist. 1994;4(1):21-37.

12. Koningsveld EA, Dul J, van Rhijn GW, Vink P. Enhancing the impact of ergonomics interventions. Ergonomics. 2005;48(5):559-80.

13. Naschold F. The politics and economics of workplace development. In: Kauppinen T, Lahtonen M, editors. National action research programmes in the 1990s. Helsinki: Ministry of Labour; 1994. Labour Policy Studies, number 86. p 109-55.

14. Pot F, Vaas F. Social innovation: the Dutch experience. Personalführung. 2008;7:40-6.

15. Volberda HW, Bosch FAJ van den, Jansen JJP. Slim managen \& innovatief organiseren [Managing smarter \& organizing innovatively]. Rotterdam (the Netherlands): Eiffel; 2006.

16. Armbruster H, Bikfabi A, Kinkel S, Lay G. Organizational innovation: the challenge of measuring non-technical innovation in large-scale surveys. Technovation. 2008;28:644-57.

17. Ligthart P, Dankbaar B, Vaessen P. Effective alignment of types of innovation in the manufacturing industry. Presentation Six Countries Program. Karlsruhe (Germany): Fraunhofer Institut ISI; 2008.

18. O'Toole J. Free to choose - how managers can create globally competitive and healthy workplaces (an American perspective). In: Weber V, editor. Achieving business excellence - health, well-being and performance. Essen Germany: Bertelsmann Stiftung/BKK; 2008. p 24-39.

19. Judge TA, Thoresen CJ, Bono JE, Patton GK. The job satisfaction - job performance relationship: a qualitative and quantitative review. Psychol Bull. 2001;127:376-407.

20. Taris TW, Schreurs PJG, Eikmans KJL, Riet P van. Werkkenmerken, welzijn en organisatieprestatie: een toets van de happy-productive worker hypothese op organisatieniveau [Work characteristics, wellbeing and organizational performance: a test of the happy-productive worker hypothesis on organization level]. Gedrag Organ. 2008;21(1):3-18.

21. Karasek RA, Theorell T. Healthy work; stress, productivity and the reconstruction of working life. New York (NY): Basic Books; 1990.

22. Sitter LU de, Hertog JF, Dankbaar B. From complex organizations with simple jobs to simple organizations with complex jobs. Hum Relat. 1997;50(5):497-534.

23. Hacker W. Action regulation theory: a practical tool for the design of modern work processes? Eur J Work Organ Psycholog. 2003;12(2):105-30.

24. Sabel CF. A real-time revolution in routines. In: Heckscher $\mathrm{C}$, Adler P, editors. The firm as a collaborative community. Oxford (NY): Oxford University Press; 2006. p 106-56.

25. Newbert SL. Empirical research on the resource-based view of the firm: an assessment and suggestions for future research. Strategic Manage J. 2006;28(2):121-46.

26. van den Bosch FAJ, Volberda HW, de Boer M. Coevolution 
of firm absorptive capacity and knowledge environment: organizational forms and combinative capabilities. Organ Sci. 1999;10(5):551-68.

27. Badura B, Greiner W, Rixgens P, Behr M, Ueberle M. Sozialkapital: Grundlagen von Gesundheit und Unternehmenserfolg [Social capital: foundation for health and company performance]. Berlin: Springer; 2008.

28. Kalmi P, Kauhanen A. Workplace innovations \& employee outcomes: evidence from Finland. Ind Relat. 2008;47(3):430-59.

29. Flood PC, Guthrie JP, Liu W. New models of high performance work systems. Dublin: National Centre for Partnership \& Performance; 2008.

30. van der Hauw PA, Pasaribu MN, van der Zeijden PT. Slimmer werken: gebruik, mogelijkheden en opbrengsten in de praktijk [Working smarter: application, opportunities and proceeds in practice]. Zoetermeer (the Netherlands): EIM; 2009.

31. Ramstad E. Unresolved couple?: the relationship between performance and quality of working life and the role of development approach. In: Pelletier, J. Intervention practices in firms. Lyon (France): ANACT; 2007. p 93-107.

32. Ramstad E. Promoting performance and the quality of working life simultaneously. Paper presented in the Workplace Participation Forum 24th September 2008.

33. Ramstad E. Innovation generating model - simultaneous development of work organization and knowledge infrastructure [dissertation]. Helsinki: Multiprint; 2008. Tykes Report 65.
34. Alasoini T, Heikkilä A, Ramstad E, Ylöstalo P. Highinvolvement innovation practices at Finnish workplaces. Int J Productivity Performance Manage. 2008;57(6):449-59.

35. Alasoini T, Heikkilä A, Ramstad E, Ylöstalo P. Promotion of participatory workplace practices through a publicly-funded programme: experiences from Finland. Paper workshop WORK-IN-NET, Rome 2008.

36. Koningsveld EAP. Factors of competitive advances through ergonomics interventions. In: Sznelwar LI, Mascia FL, Montedo UB, editors. Human factors in organizational design and management - IX. Santa Monica (CA): IEA Press; 2008. p 265-70.

37. Delery JE, Doty DH. Modes of theorizing in strategic human resources management: tests of universalistic, contingency, and configurational performance predictions. Acad Manage J. 1996:39(4):802-35.

38. Prud'homme van Reine P, Dankbaar B. Mythe en realiteit van het creëren van innovatieculturen [Myth and reality in the creation of innovation cultures ]. M\&O. 2009;3:45-59.

39. Takeuchi H, Osono E, Shimizu N. The contradictions that drive Toyota's success. Harv Bus Rev. 2008;86(6):96-104.

Received for publication: 20 July 2009 